University of Nebraska - Lincoln

DigitalCommons@University of Nebraska - Lincoln

1982

\title{
Agricultural Meteorology in China
}

Norman J. Rosenberg

University of Nebraska - Lincoln

Follow this and additional works at: https://digitalcommons.unl.edu/natrespapers

Part of the Natural Resources and Conservation Commons, Natural Resources Management and Policy Commons, and the Other Environmental Sciences Commons

Rosenberg, Norman J., "Agricultural Meteorology in China" (1982). Papers in Natural Resources. 1104. https://digitalcommons.unl.edu/natrespapers/1104

This Article is brought to you for free and open access by the Natural Resources, School of at DigitalCommons@University of Nebraska - Lincoln. It has been accepted for inclusion in Papers in Natural Resources by an authorized administrator of DigitalCommons@University of Nebraska - Lincoln. 


\begin{abstract}
During nearly five weeks in China (May-June 1981), the author visited scientific institutions and experiment stations engaged in agricultural meteorology and climatology research and teaching. The facilities, studies, and research programs at each institution are described and the scientific work in these fields is evaluated. Agricultural meteorology and climatology are faced with some unique problems and opportunities in China and progress in these fields may be of critical importance to that nation in coming years. The author includes culinary notes and comments on protocol in China.
\end{abstract}

\section{Introduction}

Following such interesting recent reports on aspects of ancient and modern meteorology in China [e.g., Wang (1979) and Reiter and Reiter (1981)], it may be "gilding the lily" to add my own. However, as the patient reader will learn, agricultural meteorology and climatology are faced with some unique problems and opportunities in China. It may not be an exaggeration to state that the progress in these fields in coming years may be of greater critical importance to that nation than would be any other branch of the atmospheric sciences.

I arrived in China 19 May 1981, a day later than planned, and returned to Lincoln at about midnight 20-21 June after what seemed a $36 \mathrm{~h}$ trip. During my nearly five weeks in China, I visited the cities of Beijing (two weeks), Nanjing (one week), Shanghai (three days) and Lanzhou and Zhungwei (six days). I returned from Zhungwei to Beijing for a two-day round-up with leaders of the five institutes in that city that are engaged in agricultural meteorology and/or climatology. My time in China primarily was spent visiting scientific institutions and experiment stations, and lecturing and leading seminars and discussions. Still, I managed to do a fair amount of touring, especially during the three-week period when my family (wife, daughter, son, and daughterin-law) was with me in Beijing, Nanjing, and Shanghai. Professor Chen Jia-yi of Beijing University travelled with me to Nanjing, Shanghai, Lanzhou, and Zhungwei, acting as my official guide and, occasionally, as interpreter.

\section{Organizations and programs}

\section{a. Beijing area}

The following organizations are engaged in agricultural

\footnotetext{
${ }^{1}$ George Holmes Professor of Agricultural Meteorology, Center for Agricultural Meteorology and Climatology, Institute of Agriculture and Natural Resources, University of Nebraska, Lincoln, Nebr. 68583-0728.
}

0003-0007/82/030250-08\$06.00

(1) 1982 American Meteorological Society meteorology and climatology research and teaching:

1) Beijing University, Department of Geophysics;

2) Beijing Agricultural University, Department of Agricultural Meteorology and Agricultural Physics;

3) Beijing Academy of Agricultural Sciences, Institute of Environmental Protection and Meteorology;

4) Institute of Geography, Academia Sinica; and

5) Chinese Academy of Agricultural Sciences, Agrometeorology Department.

6) Central Meteorological Bureau

\section{1) Beijing University, Department of GEOPHYSICS}

The Department of Geophysics is headed by Professor Xie Yibing, a meteorologist trained at the University of Chicago during the early 1940s. The Atmospheric Sciences section of the department is headed by Madame Professor Yin Zong Zhao. Associate Professor Chen Jia-yi, who was a visiting scientist at the University of Nebraska-Lincoln in the Center for Agricultural Meteorology and Climatology last year, is charged with developing a program in agricultural meteorology.

The Department of Geophysics is well equipped to teach traditional courses in meteorology, and produces capable forecasters and dynamic meteorologists. Thus far, little work has been done in the realm of agricultural meteorology within Beijing University. Their central position as the major educational institution for advanced training of meteorologists in China is of great importance, however. The university is called upon frequently to provide specialists and advice to other organizations and, indeed, many of the organizations cited below are staffed with graduates of Beijing University.

In general, a modest effort is going into some climatological descriptions and probability analyses related to Chinese agriculture. Little experimental work has yet been done in agricultural meteorology. It has been suggested that Beijing University become involved in some aspects of the carbon dioxide problem in cooperation with the United States Department of Energy. If priorities are so arranged, their skills and instrumentation in micrometeorology, which until now have been devoted primarily to problems of turbulent diffusion and air pollution, might be applied as well to agricultural problems.

\section{2) Beijing Agricultural University, DEPARTMENT OF AgRicultural METEOROLOGY AND Agricultural Physics}

Beijing Agricultural University is located in a run-down set of buildings recovered from the military, which took them during the Cultural Revolution. Much of the original campus 
is still used as a military camp.

The Agricultural Meteorology-Agricultural Physics Department of the University is headed by Professor Pei, and the Agricultural Meteorology section by Madame Han, Shan Lin. The unit carries out a wide range of research projects. Some examples of current studies involving micrometeorology: a) frost protection for orchards; b) microclimatic effects of windbreaks; c) climate control in swine housing; d) inter-cropping and relay-cropping techniques; e) heat and vapor exchange in the wheat crop; and f) light distribution in plant canopies.

Among current climatology studies now underway are: a) heat unit tabulation as a basis for determining crop scheduling; b) probabilities of low temperature risk to early and late rice; and c) growth analysis and simulation for determining climatic adaptation of major crops.

Beijing Agricultural University maintains some experimental fields close to the campus. Compared to others I saw later, the setting of this station is reasonably good, but the fields are small and irrigation ditches and other kinds of obstructions complicate the experimental set-up. At the station, I observed the use of a microwave refractometer for determination of water content in soil samples. The technique is definitely faster than oven-drying of the gravimetric technique commonly used in this country.

Beijing Agricultural University maintains a teaching program in agricultural meteorology. There are some 50 seniors in the advanced class, who began studying about four years ago. There are no junior or sophomore classes. A new freshman class was started this year. The university has produced many of the agricultural meteorologists now employed in China. New graduates will be sent to work in experiment stations when their undergraduate training is completed. Only a small number of students remain on for graduate work.

\section{3) Institute of Environmental Protection, BeiJing ACAdemy of Agricultural Sciences}

This unit is headed by Professor Liu Xing-Kuei. Professor Deng heads the agricultural meteorology group, which is engaged primarily in research work. In all, there are some 15 staff members and their major emphasis is on cereal and vegetable production in the Beijing area. Climatology studies of importance include agroclimatic zoning and determination of production potentials on the basis of thermal and light conditions.

Interesting work is being done in what the Chinese call "agroclimatic zoning." Production potential of various regions is calculated as a function of a number of climatic and geographic variables. Among the most important climatic factors are the radiation balance and the thermal regime. Interesting work also is being done on freeze damage to winter wheat. In the 90-day period from the end of November through March, freeze damage can occur because of a number of phenomena, including extrusion of plants from the ground and suffocation and exposure of the roots, due to freezing and thawing of the soil. Analysis of the impact of variety, fertilization, previous exposure to cold, and other factors is now underway.

\section{4) Institute of Geography, Academia Sinica}

There are some 30 Geographical institutes in China, of which 12 have active research programs. One of the foremost of these institutes is located in Beijing and is a part of Academia Sinica. That institute has a number of departments, one of which is Climatology. In the Climatology Department there are four major programs: a) Monsoonal Climates, b) Climatic Change, c) Microclimate and Agroclimatology, and d) Phenology.

Many interesting and relevant studies are underway in this institute, which is headed by Professor Hueng Ping-wei. The relationship between the strength of the monsoon and the occurrence of drought in the Yangtze River region is being studied. The effects of snow cover in the mountains, sea surface temperature in the Equatorial Pacific Ocean, and other factors are studied in the search for tools to aid in long-range forecasts of precipitation for central and eastern China.

Paleoclimatic studies of the period from the 15th through the 18th centuries now are underway. During the Ming and Ch'ing dynasties, regional geographical records were carefully made so that archives of data on floods, droughts, and many other climatic events are now available for study by paleoclimatologists. Efforts are made to calibrate dendrochronological data against these and other forms of records.

As is probably well known, the Chinese have the best and most complete phenological records that exist (see Wang, 1979). Their record goes back for over 2,000 years; each year is subdivided into 24 solar terms (two-week periods). These observations continue today with a network of 58 phenological observation stations maintained throughout China. The phenology of all major crops is recorded. The poplar and willow are also closely observed, as are certain animals. The dates of river freezing, melting of snow, the migration of birds, and other events also are recorded regularly.

Studies are underway now on the local microclimates in rubber tree cultivation in tropical regions of China. The rubber tree is subject to frost damage to the trunks, especially, and techniques for protection are being sought. Topoclimatological studies are being done in Hunan province, where the freezing of rubber trees is clearly related to slope and topography.

One of the most interesting studies I heard about involves a climatological analysis of the Tibetan plateau. Much of the farming in Tibet occurs at altitudes of $4,000 \mathrm{~m}$ or aboveright smack in the middle of the troposphere. There, the incoming solar radiation is intense and the flux density of ultraviolet radiation is very high. Normal rainfall is fairly scanty, declining from $400-800 \mathrm{~mm}$ east of Lhasa to 200 $400 \mathrm{~mm}$ west of that city. Warm season temperatures are low, winter temperatures are not. There is a low absolute concentration of carbon dioxide because of the altitude. Despite these strange circumstances, yields of cool season crops such as barley, broadbeans, peas, and potatoes are extremely high. This probably is due to an extremely long growing season. Certain crops require more than a full year in order to reach maturity. Quality of the crops is also very good. For example, sugar beets yield $20-22 \%$ sugar; rapeseed yields $51 \%$ oil. 


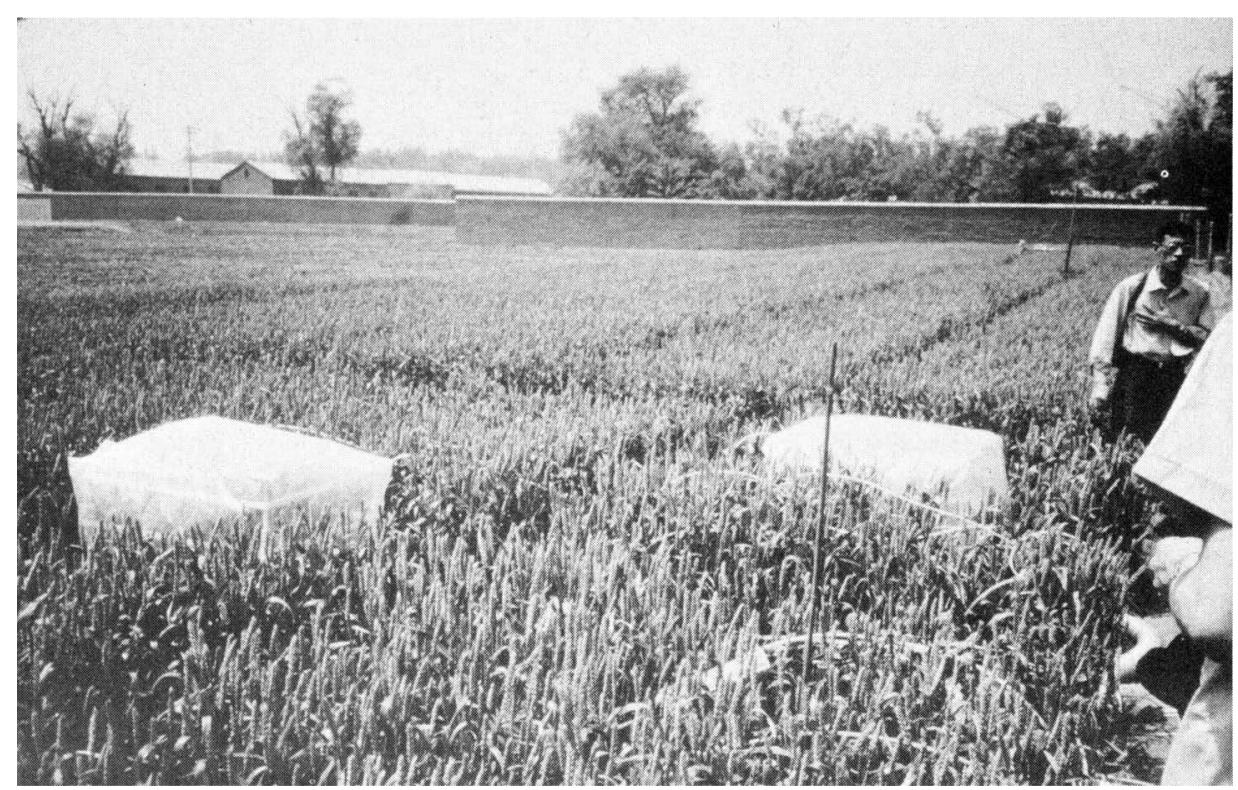

FIG. 1. Plastic covered chambers used for study of photosynthesis and transpiration in wheat. The experimental field is one being developed by the Academy of Agricultural Sciences in Beijing.

From the foregoing, it will be clear that the program of the Geographical Institute is wide-ranging. In fact, they have an active experimental program of microclimatic research with field crops and specialty crops. The Geographical Institute is planning to develop a new experimental facility with a land area of about 60 hectares. The station will be located in the vicinity of Beijing.

\section{5) Agricultural Meteorology Department, ACADEMY OF AgRicultural SCIENCES}

This organization is engaged in research, primarily. Professor Liu Ming-Xiao is head of the Agricultural Meteorology Department. Their program involves studies of photosynthesis and photosynthetic potential and their agroclimatological analyses are aimed at regionalization of major crops. They also are engaged in a study of major meteorological disasters such as drought and floods in north China, and frost damage to sensitive crops throughout the country. Studies of livestock performance as related to weather conditions also are underway.

I visited a newly developed experimental field facility near the institute (Fig. 1). A $6 \mathrm{~m}$ tower and lysimeters are to be built in this field in the near future. Unfortunately, the field already is being encroached upon by factories and residences. Smoke pollution is significant and the useful life of stations of this sort may be short.

I did note that the instrumentation used at this station is quite advanced and innovative. There were miniature strip radiometers and psychrometers of a type $I$ have not seen before. The technical skill in instrumentation at this institute seems superior.

\section{6) Central Meteorological Bureau}

I paid a short visit to the headquarters of the Central Meteorological Bureau, which also is located in Beijing. This organization is the Chinese equivalent of our National Weather Service. The building and facilities are devoted primarily to forecast-related activities. Equipment seems quite good-radars, APT receivers, computers, etc., are relatively up-to-date.

The Central Meteorological Bureau has a small group engaged in agrometeorology at its Beijing headquarters. Their major efforts are in the regionalization and description of China's climates on the basis of radiation, temperature, and humidity conditions. The effects of natural disasters on crop production also are being studied; e.g., low temperature impacts on early and late rice. The preparation of longrange, seasonal forecasts by means of various modeling techniques is a major activity of the group. They also are developing indices of productivity based on the duration of sunshine. In another study, the meteorological factors involved in insect migrations are being examined. Times of biological activity must coincide with certain meteorological conditions in order for landings and take-offs by swarms of insects to occur.

The Central Meteorological Bureau is responsible for the Meteorological Institute in Nanjing. Most of the meteorologists employed by the Bureau are trained at that institute.

\section{b. Other areas}

\section{1) Meteorological Institute, Nanjing}

This institute is primarily devoted to teaching and training 

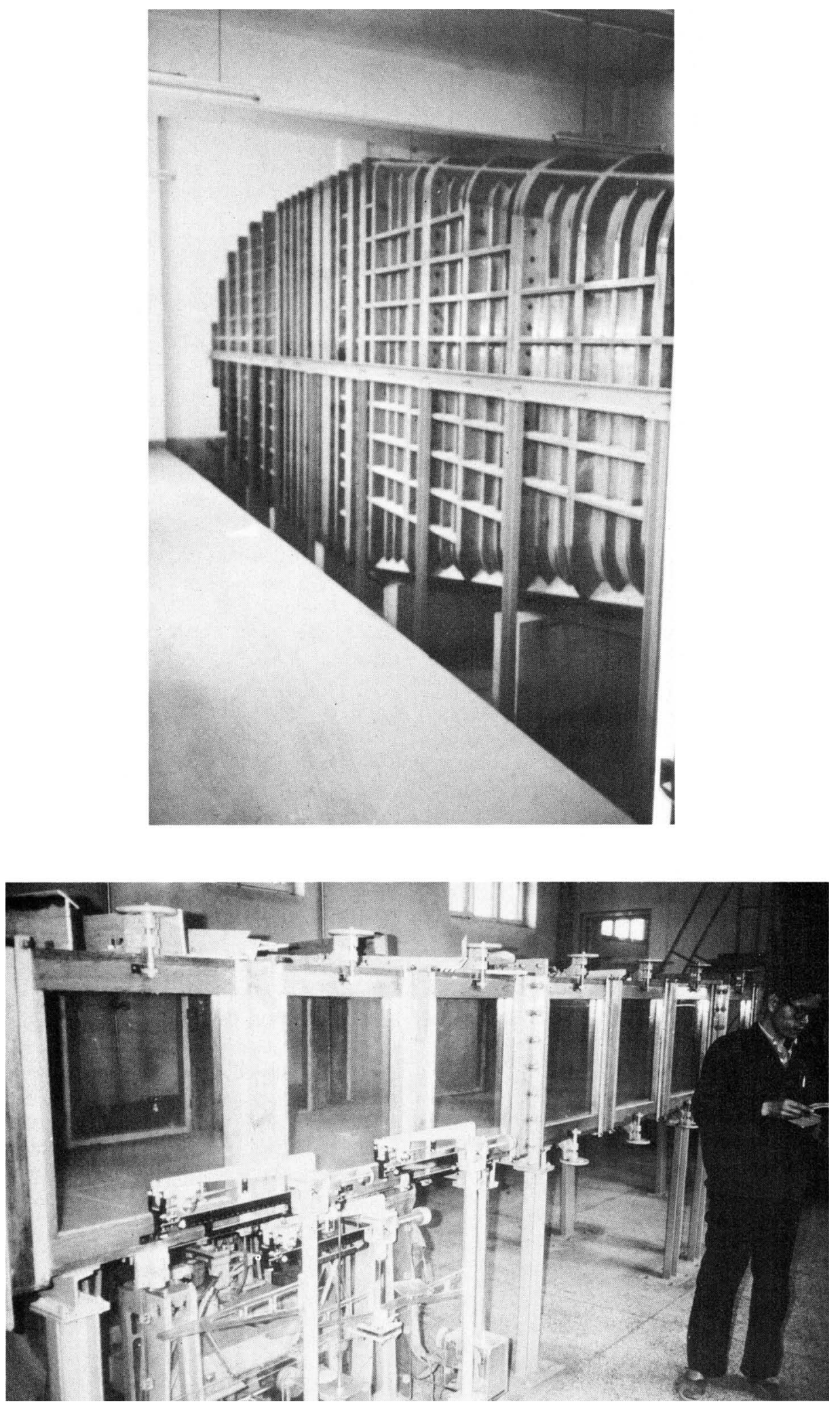

FIG. 2. a) Source area and b) test section of the Desert Research Institute wind tunnel. 
meteorologists to serve with the Central Meteorological Bureau. There are only three departments: Atmospheric Physics, Basic Courses, and Agrometeorology. The institute itself is fairly well endowed, although the buildings currently in use are rather old. A new headquarters building is being constructed on the campus. Students and faculty reside on the campus, which is about a 45 min drive across the Yangtze River from the center of Nanjing.

The teaching laboratories I visited are not well equipped by our standards, but there seems to be a little bit of everything available. Eventually the students are exposed to all of the instrumentation that is discussed in their courses. The general curriculum for agrometeorologists involves physics and chemistry (38\%), agronomy (12\%), languages and physical education (22\%), meteorology (15\%), and agrometeorology (13\%). A student thesis is required for graduation.

The Institute is engaged in a number of research activities. China leads the world in development of hybrid rice. Since rice is subject to low temperature damage and there are also variations in its adaptation to different geographical locations, climatic classifications are needed to ensure that proper mating times for various hybrids can be chosen. Meteorological conditions required for the climatic adaptation of hybrid rice are now under study. There is also a project underway in forecasting frosts of agrometeorological importance. Adaptation of wheat in southern China is restricted by high temperatures and excessive precipitation. Studies are underway to help designate the appropriate regions for the wheat crop.

The Nanjing Institute conducts numerous research projects in cooperaton with other institutes within the region they serve. The institute also is trying to develop experimental skills to conduct studies of radiation and thermal regime in various field crops. A small experiment station has been built adjacent to the grounds of the institute. The station is set below the general topography of the institute and thus may be a drainage way for cold air. I recommended that they consider moving their station onto farmland adjacent to the institute.

\section{2) Institute of Plant Physiology, Shanghai}

The institute of Plant Physiology in Shanghai is one constituent unit of Academia Sinica. Their mission is the conduct of fundamental research on photosynthesis. Most of their work involves the molecular or biochemical level. However, there is a small group headed by Dr. Wang Tien-duo, doing research in physiological ecology.

Reprints I have studied indicate significant activity during the early 1960s, when important contributions were made in growth analysis and the study of cropping potentials. Now, Professor Wang is rebuilding with a pair of "graduate" students. These are men who somehow managed to study on their own during the Cultural Revolution. Although they lack official degrees, they are considered extremely capable and able to undertake research with a minimum of direction.

\section{3) Desert Research Institute, Lanzhou}

From Shanghai, I flew west to Lanzhou-about midway across China-to visit the Desert Research Institute, which is also a part of Academia Sinica. The institute, headed by Professor Zhu Zhendu, is a spin-off from glaciology institute.

Lanzhou is in the middle of a semi-arid region. The region appears more arid than semi-arid, because the land is virtually denuded of all vegetation except in the valleys, where some irrigation and dryland agriculture is practiced.

The Desert Research Institute has a very broad program of research involving climatology, meteorology, physiological ecology, plant physiology, and many other disciplines. Their primary objectives are development of techniques for stabilizing sand dune movement and reclaiming the deserts. The staff seems convinced that the deserts of China are to a large extent man-made, and that there are methods that can be used to reverse the process of desertification.

I gave a number of lectures in Lanzhou, particularly on the use of windbreaks and reflectant materials to relieve water stress on plants and increase water efficiency. I would say that the Chinese have as much experience with windbreaks as we do. The institute has constructed a very impressive wind tunnel (Fig. 2) in which techniques for controlling blowing sands with windbreaks are studied. It is obvious that the research has been well extended. I was quite impressed by systems of windbreaks that I saw later in farming areas along the Yellow River.

The idea of using reflectants on plants is a new one for the Chinese. In the case of labor intensive anti-desertification work, it may be a practical idea. ${ }^{2}$ At any rate, I expect that the people of the Desert Research Institute will be giving this technique considerable thought, and may undertake some experiments in the coming years.

Much of the work of the institute staff is carried out at an experiment station called Sabatou, $20 \mathrm{~km}$ west of the town of Zhungwei. Zhungwei is about seven hours northeast of Lanzhou on the railway line to Beijing. That line runs, literally, through a large area of moving sand dunes at the south edge of the Gobi-the Tangeray Desert. A great deal of effort has gone into stabilizing the sand dunes to protect the railway line. The work involves mechanical stabilization of the dunes through the establishment of a checkerboard pattern of straw barriers (Fig. 3). Other types of mechanical barriers also are used. A wide range of shrubs, notably Salix and Carragonia, and trees, especially Poplar, are planted into the straw-stabilized dunes. A strip of land about $1 \mathrm{~km}$ wide and $40 \mathrm{~km}$ long has already been stabilized to protect the railway lines.

The Sabatou Experiment Station, headed by Wang Kang$\mathrm{fu}$, lies about $80 \mathrm{~m}$ below the rail line and some $20-30 \mathrm{~m}$ above the Yellow River. At the site of the experiment station, dunes have been leveled for the planting of a wide range of fruit, vegetable, grain, and forage crops. The farmed area is about $40-50$ hectares in size and is protected on all sides by tree windbreaks (Fig. 4).

\footnotetext{
${ }^{2}$ For a description of this technique, see Rosenberg, N. J., 1974. Microclimate. The Biological Environment. John Wiley, New York. pp. 281-293.
} 


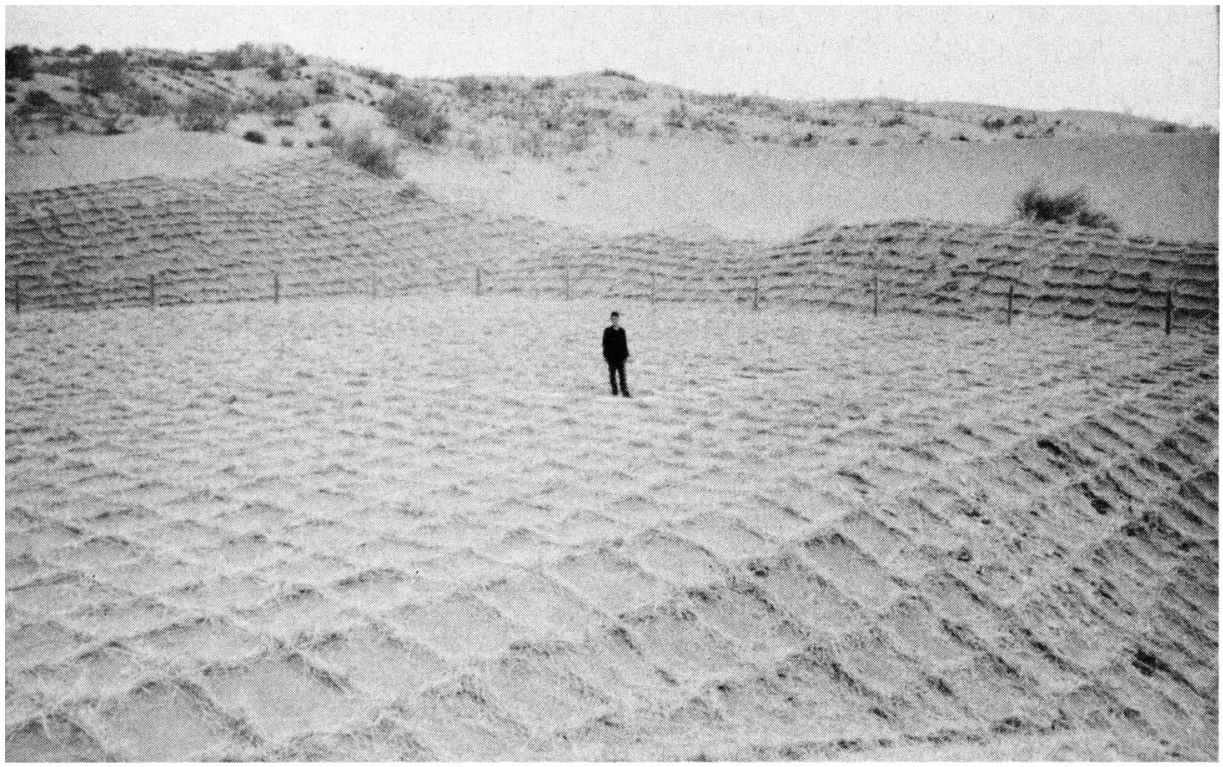

FIG. 3. The "straw-checkerboard" method for stabilizing sand dunes. Straw is driven into the sand with a spade in the pattern shown. Shrubs and grasses are planted in the boxes and take root during the two or three years that the straw serves to hold the sand in place. A scientist of the Desert Research Institute is standing at the corner of a drainage lysimeter used to measure evapotranspiration from the stabilized sand.

Irrigation is with water drawn from some distance upstream on the Yellow River. As its name indicates, the Yellow River is a very silty body of water and its use leads to an enrichment of the dune sands. I examined soil profiles that show the change in texture that occurs over a number of years. Virtually all of the irrigation is done by flooding, and this leads to considerable leaching of fertilizers out of the soil. However, the convenience of flood irrigation and the advantage of silt deposition seems to overweigh this loss. I was extremely impressed by the work I saw at the Sabatou location, including both dune stabilization and farming. From what I recall of similar efforts in other parts of the world, I would say that the work here is exemplary.

The station itself is reasonably well endowed by Chinese standards. All of the instrumentation for soil chemical and physical analysis that I observed was circa 1960 . However, the lack of up-to-date computerized electronic equipment is really, in my opinion, no great burden. The instrumentation

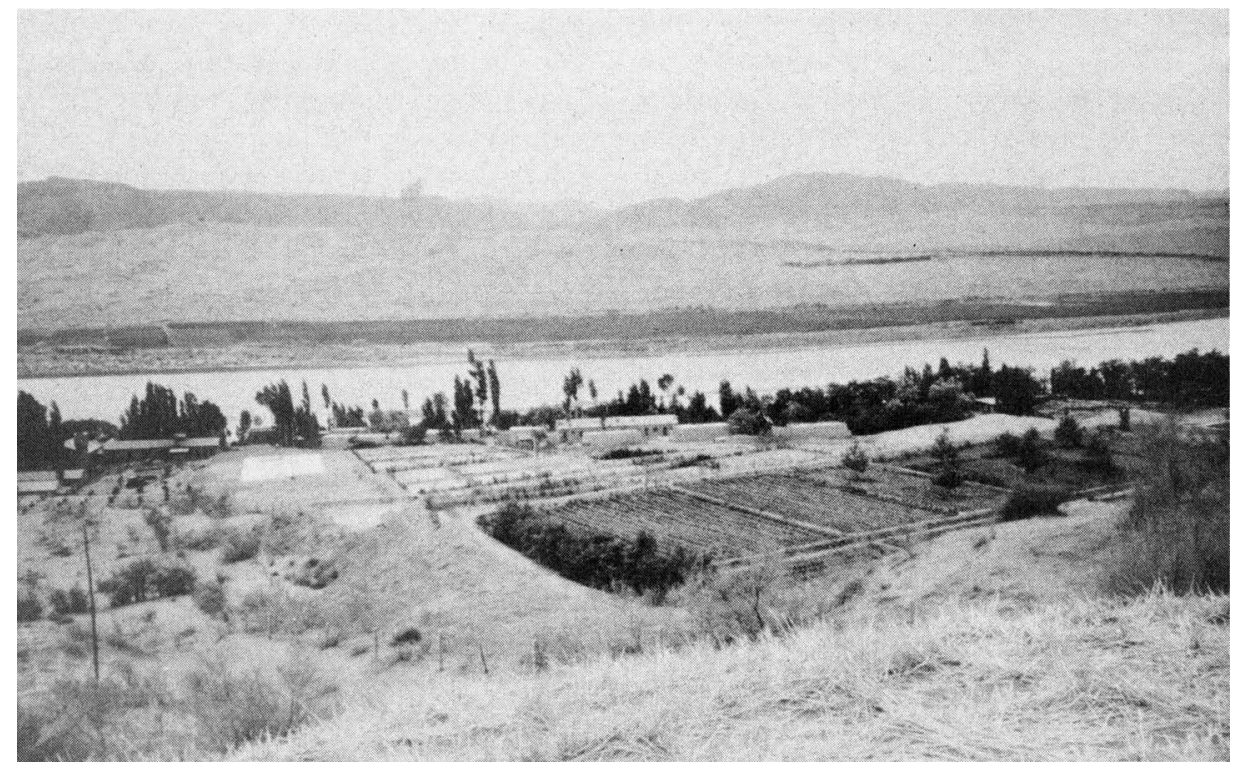

Fig. 4. A view of the Sabatou Experiment Station above the Yellow River, where a wide range of horticultural and agronomic crops are grown on leveled and stabilized sand dunes. 
they have is accurate enough for its purpose, and there is a large staff able to operate the equipment. The labor savings afforded by computerization would be of no great consequence here.

Micrometeorology research is not well developed at the Sabatou Station. There are some very interesting opportunities for research, considering the new microclimates developed by the irrigated farm. Despite the system of tree windbreaks that surrounds the farm, some sand-blowing still occurs. I recommended that they try growing tall annual crops in strips as supplemental windbreaks.

From Zhungwei, Professor Chen and I boarded the train from Lanzhou for the long $(30 \mathrm{~h})$ ride back to Beiiing. But that is another story!

\section{Lectures}

I gave four lectures in Beijing, each one at a different institution. For the most part, the audience followed me from place to place, so I was able to treat these lectures as a series rather than as separate subjects. The lectures were:

1) Agricultural Meteorology in the United States and Canada. This was a discussion of the major weather-related problems in United States and Canadian agriculture, and an identification of the universities and governmental agencies involved in research on these problems.

2) Water use efficiency in agricultural production. This lecture dealt primarily with research on windbreaks and reflectants conducted in Nebraska and other Great Plains states.

3) Advection of sensible heat and the determination of water demand by resistance and eddy-correlation methods.

4) Possible impacts of the increasing $\mathrm{CO}_{2}$ concentration in the atmosphere on world agriculture.

With some reshuffling and reordering, the same material was given in four lectures in Nanjing. All my lectures in Nanjing were given at the Meteorological Institute. In Shanghai I presented lectures 1) and 4), and in Lanzhou, lectures 2) and 3). I gave no lectures in Zhungwei, but held a seminar for the staff there.

\section{Program of visits}

My visits to the various institutes generally began with a presentation by my hosts on their programs and activities. Between lectures there were visits to experiment stations and laboratories. Near the end of my stay in each city, open discussion and question/answer sessions were held. These were very valuable for me since, from the questions asked, I was better able to determine the level of experience of the staff and especially to understand the nature of the problems they face in their work.

\section{Culinary notes}

Sometime during my stay in each of the cities, dinners were held in honor of our family. There were three banquet dinners in Beijing, each hosted by a different institution, and one each in Nanjing and Lanzhou. We were also dinner guests at the homes of a number of colleagues. I was able to reciprocate some of the hospitality with a dinner in Nanjing in honor of the second wedding anniversary of our son and daughter-in-law. We also hosted a "no-excuse" dinner in Shanghai for colleagues and new friends. This dinner was held prior to my family separating. I went to Lanzhou, Zhungwei, and back to Beijing, and the rest of the family travelled to Hanzhou, Hong Kong, and then home.

To describe these dinners in detail would take pages, if not volumes. Suffice it to say that setting a "world famous chowhound" like me loose in their country may have set back the Chinese plans for self-sufficiency in food considerably. Chinese food is fabulous!

A final culinary note: On my last night in Beijing, Professor Xie hosted yet another dinner - this one on the grounds of Beijing University. The fellowship as well as the food will long be remembered.

\section{Interpreters}

I was very fortunate to have had the help of some excellent interpreters as I travelled around the country. Professor Chen travelled with me and handled all the mechanics of the tour. In Beijing, Professor Liu Han-Chung, an agricultural meteorologist of the Agricultural University interpreted very ably in fluent English. In Nanjing, Professor Wong of the Nanjing Botanical Gardens did the job. He was less familiar with the meteorology in my lectures, so Professor Chen helped considerably. In Shanghai, Professor Wang Tien-duo of the Institute for Photosynthesis Research was my interpreter. His English is perfectly fluent. As he is a physiological ecologist, he had very little trouble with the subject matter. In fact, he had heard all of my lectures in Beijing. In Lanzhou and Zhungwei, Professor Chen did the scientific interpretations. It is interesting that, except for Chen, those interpreters had each learned English in China without benefit of time in English-speaking countries.

\section{Protocol}

Protocol and extreme, but genuine, courtesy are very much a part of the Chinese way. We were always met at airports and train stations. In Nanjing, the entire staff of the agricultural meteorology group of the Meteorological Institute was waiting at the station to greet us. After a week of activities, they were all there again to see us off to Shanghai.

Vice Presidents of the major organizations held formal receptions for us and hosted the dinners mentioned above. At every arrival for a lecture or appointment, the appropriate officials were waiting on the steps to greet us. Perhaps the 
most extreme manifestation of Chinese courtesy occurred as Professor Chen and I departed by train from Zhungwei for Beijing. ${ }^{3}$ Four staff members had accompanied us to Zhungwei from Lanzhou. The train ride took seven hours. The train back to Lanzhou leaves each day at 2:30 p.m.; the train for Beijing at 3:02 p.m. The Lanzhou people remained one day longer in Zhungwei simply to be able to participate in our send-off! I was astounded to learn that they had inconvenienced themselves in a way that to me seemed so unnecessary. Professor Chen explained to me that it would have been most discourteous for them to have done otherwise.

\section{Quality of the scientific work in agricultural meteorology}

This section will, necessarily, be chock-full of generalities. All of the institutions I visited are doing some kind of climatological analysis. The work ranges from simple and repetitive data organization and summarization to quite advanced analysis of climatic zonation and productivity potentials. Most of the work lies between these extremes, and involves computations of various standard indices of potential evapotranspiration or thermal conditions based on heat units.

In the realm of micrometeorology and microclimate research, the picture is more complicated. There are many good theoreticians among the older Chinese scientists (40 years + ). Virtually no field experimentation or instrumental development took place during the Cultural Revolution, so skill and experience in this realm are clearly lacking.

The Chinese have developed some very interesting multiple-cropping schemes involving intercropping and relay cropping systems. Straight-forward agronomic tests of these methods are well managed. But, since fields in the Beijing area are small, microtopography is complex (due to the presence of irrigation ditches and bunds, trees, etc.), and houses and factories are too near, it is very difficult to do good microclimate studies in the experimental fields that are available to the several institutes.

Most instruments are "homemade" and based on copies of western, Russian, or Japanese equipment. I saw the "spitting-image" of some instruments with which I have worked (even some lousy ones)-including infrared gas analyzers, Assman psychrometers, and many other standard sensors.

Although their instruments are reasonably well made, I observed that many workers were unaware of systematic errors in the measurements they were making. It is in the

\footnotetext{
${ }^{3}$ Zhungwei is about one-fourth of the way between Lanzhou and Beijing on the rail line that connects these cities (a $36 \mathrm{~h}$ ride).
}

realm of field experimentation that the Chinese agricultural meteorologists seem to need the most help.

The generalizations given above can apply, as well, to the Desert Research Institute in Lanzhou. Yet the difficulty of the environment in which they work (Lanzhou headquarters, Zhungwei, and other desert experiment stations) together with the awesomeness of the problems they deal withstabilization of hundreds of square kilometers of sand dunes and reversing desertification of agricultural lands-makes their achievements appear very dramatic. True, that institute has a good feel for public relations and they show themselves well.

After returning from Zhungwei, I spent a final day in Beijing and met there with the directors of the five Beijing institutions described above. I summarized for them the impressions I had gained in China and presented a number of ideas for general discussion. These discussions concerned ways to coordinate the work of the several institutions in the Beijing area, including development of a single major experiment station to serve all their needs. The need for a central instrumentation and calibration facility for agrometeorological research also was discussed.

Because of the small fields and complicated agriculture practiced in the region, a need was identified for miniaturized instrument packages that can be placed very near the surfaces of the crop and within the crop canopy. Mobility of equipment so that experiments can be accomplished in representative farm sites, away from permanent experimental fields, was emphasized.

Most institutes I visited have received permission to send one or two people abroad for advanced study in agrometeorology. We discussed places in the United States and Canada where the needs of these scholars might best be served. The exchange of scholars, of course, offers the best possibility for realizing the potential benefits that China, the United States, and Canada can gain from one another's accumulated knowledge and experience.

Acknowledgments. Through Grant ATM-7901017, the National Science Foundation, Atmospheric Sciences Division, provided the funds needed to get me to China (and back). Beijing University and other Chinese Institutes supported my travel within China. Ms. Betty James made a readable manuscript out of my virtually illegible notes.

\section{References}

Reiter, E. R., and G. J. Reiter, 1981: Tibet-The last frontier. Bull. Am. Meteorol. Soc. 62, 4-13.

Wang P. K., 1979: Meteorological records from ancient chronicles of China. Bull. Am. Meteorol. Soc. 60, 313-318. 